\title{
Alimentação em unidades de educação infantil: planejamento, processo produtivo, distribuição e adequação da refeição principal ${ }^{\#}$ Meals in children's education units: planning, production process, distribution and adequacy of the main meal

\author{
Estefanini Libia Siqueira Teixeira de Almeida* \\ Michelle Franklin Silva Fontes** \\ Adriana Versiani dos Anjos*** \\ Luana Caroline dos Santos s** $^{* *}$ \\ Simone Cardoso Lisboa Pereira****
}

\section{Resumo}

O objetivo deste estudo foi avaliar o planejamento, processo produtivo, distribuição e adequação nutricional à legislação nacional vigente da refeição principal ofertada em unidades de educação infantil do município de Belo Horizonte, Minas Gerais-Brasil. Trata-se de um estudo descritivo transversal realizado de julho de 2012 a julho de 2013, com uma amostra representativa ( $\mathrm{n}=73$ ) das unidades de educação infantil dos nove distritos sanitários de Belo Horizonte. Foi verificado se os índices de produção e adequação nutricional estavam em consonância com as diretrizes do Programa Nacional de Alimentação Escolar-PNAE, por meio da pesagem direta de cinco cardápios da refeição principal, coletados randomicamente. Constatou-se que $78,4 \%$ dos cardápios produzidos sofreram alteração em comparação aos planejados. Identificou-se índices elevados de resto ingestão $(7,08 \%)$ e do somatório das sobras de produção e distribuição (8,55\%). Inadequações nutricionais foram verificadas nos cardápios planejados pelo município e produzidos nas unidades, uma vez que a maioria não atingiu os valores de referência estabelecidos pelo PNAE. Adicionalmente, correlações foram identificadas entre a quantidade produzida com a porção consumida pelos alunos $(r=0,198 ; p<0,001)$, a porcentagem de sobra limpa $(r=0,267 ; p<0,001)$ e a porcentagem de sobra suja $(r=-0,255 ; p<0,001)$. Além disso, foi percebida correlação entre a porcentagem de sobra limpa com a porcentagem de resto ingestão $(r=-0,254 ; p<0,001)$. Portanto, levantou-se a demanda de reestruturação dos cardápios planejados pelo município e da garantia de que sejam executados pelas unidades de educação infantil, acompanhados de ações educativas que promovam a alimentação saudável e a redução dos índices de desperdício.

Palavras-chave: Alimentação Escolar. Educação Infantil. Planejamento de Cardápio. Desperdício de Alimentos. Recomendações Nutricionais.

\begin{abstract}
The aim of this study was to evaluate the planning, production process, distribution and nutritional adequacy of the main meal offered in children's education units in the municipality of Belo Horizonte, Minas Gerais, Brazil, in relation to the current national legislation. This was a descriptive cross-sectional study conducted between July 2012 and July 2013, on a representative sample $(n=73)$ of children's education units in nine healthcare districts in Belo Horizonte. It was investigated whether the production and nutritional adequacy indexes were consonant with the guidelines of the National School Meals Program (PNAE), by means of direct weighing of five menus for the main meal that were gathered randomly. It was observed that $78.4 \%$ of the menus produced had undergone changes, in comparison with what had been planned. High rates of remnant food $(7.08 \%)$ and combined production and distribution leftovers $(8.55 \%)$ were seen. Nutritional inadequacies were found in the menus planned by the municipality and produced in the units, since most of them did not attain the reference values established by the PNAE. In addition, correlations between the quantity produced and the portion consumed by the students $(r=0.198 ; p<0.001)$, the percentage of clean leftovers $(r=0.267 ; p<0.001)$ and the percentage of dirty leftovers $(r=-0.255 ; p<0.001)$ were identified. Furthermore, a correlation between the percentage of clean leftovers and the percentage of food remnants was seen $(r=-0.254 ; p<0.001)$. Therefore, a requirement for restructuring of the menus planned by the municipality and for ensuring that these will be implemented by the children's education units was identified, accompanied by the need for educational actions that would promote healthy eating and reduction of the wastage rates.
\end{abstract}

Keywords: School Meals. Children's Education. Menu Planning. Food Wastage. Nutritional Recommendations.

DOI: $10.15343 / 0104-7809.20153903333344$

\# O presente estudo foi financiado pela Fundação de Amparo à Pesquisa do Estado de Minas Gerais - FAPEMIG, Processo APQ-02812-13.

* Universidade Federal de Minas Gerais. Belo Horizonte, MG - Brasil. E-mail: estefaninilibia@yahoo.com.br.

** Secretaria de Educação. Belo Horizonte, MG, Brasil. E-mail: michellefontes.nutri@yahoo.com.br.

*** Secretaria Municipal Adjunta de Segurança Alimentar e Nutricional. Belo Horizonte, MG - Brasil. E-mail: driarroba@gmail.com.

**** Universidade Federal de Minas Gerais. Belo Horizonte, Minas Gerais, Brasil. E-mail: luanacs@ig.com.br.

***** Universidade Federal de Minas Gerais. Belo Horizonte, MG - Brasil. E-mail: simoneclpereira@gmail.com.

Os autores declaram não haver conflitos de interesse. 


\section{INTRODUÇÃO}

A infância representa um estágio fundamental para a aquisição de hábitos alimentares saudáveis, os quais garantirão o crescimento e desenvolvimento da população inserida neste grupo. Ressalta-se que, essa fase da vida é caracterizada por uma intensa vulnerabilidade biológica, na qual a população infantil se vê cendo, portanto, uma atenção especial ${ }^{1}$. Uma criança desnutrida ou obesa apresenta grandes chances de se tornar um adulto obeso ou portador de outros distúrbios nutricionais associados, como Diabetes Mellitus, Hipertensão Arterial e Dislipidemias ${ }^{2}$.

Tendo em vista as consequências supracitadas, bem como a importância das experiências alimentares na infância, identifica-se o ambiente escolar como um espaço tanto de ensino, como de desenvolvimento de ações voltadas para a melhoria do estado nutricional das crianças, promovendo sua saúde. Na infância, a escola é um ambiente fundamental para a determinação de hábitos, uma vez que o aluno permanece no local em período parcial ou integral, interagindo com educadores, manipuladores de alimentos e outras crianças que irão gerar influências em seu estilo de vida ${ }^{3}$. As instituições de ensino proporcionam um ambiente desafiador, onde estão inseridas diversas atividades, dentre elas a alimentação escolar. Essa prática é cotidiana na maioria das instituições, envolvida por uma cultura particular ${ }^{4}$.

Segundo o artigo 208 da Constituição Federal de 1988, a alimentação para alunos da rede pública passou a ser considerada um direito garantido por meio de um programa social: o Programa Nacional de Alimentação Escolar PNAE. Este tem como principais objetivos a contribuição para o crescimento e desenvolvimento da população infantil, o rendimento escolar e a promoção de hábitos alimentares saudáveis. Para alcançá-los, o PNAE busca introduzir refeições que ofereçam as necessidades nutricionais do público infantil em todo o período letivo e realiza intervenções visando à educação alimentar e nutricional ${ }^{5}$.

Considerando o fato de que as unidades de educação infantil vêm ganhando cada vez mais adeptos, um dos principais desafios enfrentados pelo PNAE nessas instituições é a aderência, de forma integral, dos membros da comunidade escolar em busca de uma alimentação saudável ${ }^{6}$. Em face deste cenário, se torna imprescindível pensar no ritual alimentar não apenas como um possível caminho para a melhora de aspectos nutricionais, mas também para o aprimoramento de aspectos relacionados à aprendizagem e à prevenção de doenças e agravos não transmissíveis uma vez que esses podem ser evitados por meio da atuação de diferentes profissionais, agindo a favor da manutenção e promoção da saúde desde a infância ${ }^{7}$. Longo-Silva e colaboradores $^{8}$ realizaram um estudo mostrando que um monitoramento e ações nutricionais nessas unidades tornam-se ferramentas necessárias para uma adequada alimentação, suprindo de forma equilibrada as demandas dos pré-escolares.

Diante do exposto, o presente estudo tem como objetivo avaliar o processo de planejamento, produção, distribuição e adequação nutricional da refeição principal em unidades de educação infantil do município de Belo Horizonte, MG.

\section{MÉTODOS}

Este estudo é de caráter descritivo com delineamento transversal, realizado no período de julho de 2012 a julho de 2013, em Unidades Municipais de Educação Infantil (UMEI) e creches conveniadas à Prefeitura Municipal de Belo Horizonte - MG.

Para o desenvolvimento do estudo abrangeu-se os nove distritos sanitários do município, totalizando 73 unidades de educação infantil. Para a amostragem, foi realizado o cálculo para fins descritivos empregando fórmulas propostas por Browner et al. ${ }^{10}$ e considerando todas as UMEl e creches conveniadas à prefeitura e a proporcionalidade pelos distritos sanitários do município, erro alfa de $5 \%$ e poder do teste de $90 \%$.

O protocolo de estudo contemplou a avaliação dos cardápios planejados pelo município e dos cardápios produzidos nas unidades de 
acordo com os respectivos per capitas. Para tal, foram selecionados de modo randômico cinco cardápios (par: planejado/produzido) em cada unidade por meio da pesagem direta de todos os ingredientes e alimentos envolvidos. ${ }^{11}$

Primeiramente, investigou-se a adesão das preparações produzidas àquelas planejadas, sendo verificado com os manipuladores de alimentos o motivo das alterações, quando cabível.

Foram utilizadas, após a devida calibração, balanças mecânicas das próprias unidades com capacidade para até $150 \mathrm{~kg}$. Dentre os pesos aferidos incluiu-se peso bruto, líquido e pós-cocção de todos os ingredientes, além de sobra limpa, sobra suja, resto ingestão e peso das porções ofertadas para crianças e colaboradores (professores, monitores, coordenação, direção e auxiliares administrativos e da limpeza). Entende-se por sobra limpa os alimentos produzidos e não distribuídos, cujas quantidades indevidas caracterizam uma forma de desperdício. ${ }^{12}$ Já a sobra suja de acordo com Soares et al. ${ }^{13}$ são aqueles alimentos que vão para o balcão de distribuição, porém não são servidos para os alunos. O percentual resto ingestão é a relação entre o resto devolvido no prato e a quantidade de alimento e preparações oferecidas, sendo determinado pelo peso do alimento retornado no prato depois de retirada as cascas de frutas e ossos. ${ }^{14}$

Quadro 1. Fórmulas dos índices avaliados, Belo Horizonte - MG, 2013.

\section{Fórmulas dos índices avaliados}

Quantidade produzida $(\mathbf{Q P})=\sum$ (em $\mathrm{Kg}$ ) de todas as preparações produzidas

Sobra limpa $(\mathbf{S L})=\sum$ (em $\mathrm{Kg}$ ) de todas as preparações produzidas e não distribuídas.

Percentual de sobra limpa $=\mathrm{SL} / \mathrm{QP} \times 100$

Sobra suja (SS) $=\sum$ (em $\mathrm{Kg}$ ) de todas as preparações que foram para a distribuição e não foram servidas.

Percentual de sobra suja $=$ SS/QP X100

Resto ingestão $(\mathbf{R I})=\sum$ (em $\mathrm{Kg}$ ) de todas as preparações devolvidas no prato

Percentual de resto ingestão $=\mathrm{Rl} / \mathrm{QP}-(\mathrm{SL}+\mathrm{SS}) \mathrm{X} 100$

Os cálculos das quantidades de alimentos produzidos e o per capita das porções ofertadas e consumidas pelos alunos foram realizados com base nos registros supracitados. O per capita oferecido foi calculado pela subtração do peso total de cada preparação executada, da quantidade consumida pelos colaboradores e dos valores das sobras limpa e suja, dividindo-se este resultado pelo número de refeições servidas para as crianças. Já o per capita consumido subtraiu-se, além dos valores citados anteriormente, o resto ingestão. Foi considerada aceitável a porcentagem de resto ingestão de 2 a $5 \%$ da quantidade servida e admissível o percentual de 3\% para o somatório de sobras limpa e suja. ${ }^{14,15}$

Quadro 2. Fórmulas dos índices avaliados, Belo Horizonte - MG, 2013.

\section{Fórmulas dos índices avaliados}

Quantidade consumida pelos colaboradores $(\mathbf{Q C C})=\sum$ (em g) de todas as preparações que compõe o prato do colaborador $X$ número de colaboradores

Per capta das porções ofertadas aos alunos $=\mathrm{QP}-(\mathrm{SL}+\mathrm{SS}+\mathrm{QCC}) /$ número de alunos

Per capta das porções consumidas pelos alunos $=\mathrm{QP}-(\mathrm{SL}+\mathrm{SS}+\mathrm{RI}+\mathrm{QCC}) /$ número de alunos

Em relação à adequação nutricional, compararam-se os valores nutricionais obtidos, tanto dos cardápios planejados pelo município quanto dos produzidos nas unidades, aos valores de referência estabelecidos pelo Programa Nacional de Alimentação Escolar, PNAE. ${ }^{5}$ Os nutrientes avaliados foram energia, carboidratos, proteínas, lipídeos, fibras, vitaminas A e C, cálcio, 
ferro, zinco e magnésio, sendo todos quantificados pela utilização do software AVANUTRI ${ }^{\circledR}$ 4.0.

Nesta comparação também foi considerada a adequação da porcentagem, $20 \%$ ou $30 \%$, dos valores nutricionais que são ofertados e os que são estipulados pelo PNAE, considerando apenas a refeição principal e o tempo que os alunos passam nessas unidades, parcial ou in-

O estudo foi aprovado pelo Comitê de Ética em Pesquisa da Universidade Federal de Minas Gerais sob o número Certificado de Apresentação para Apreciação Ética de 00734412.0.0000.51.

As informações foram armazenadas em um banco de dados construído no programa Microsoft Office Excel $2007^{\circledR}$. A análise estatística foi realizada com auxílio do software Statistical Package for the Social Science (SPSS), versão 19.0 for Windows ${ }^{\circledR}$.

Efetuou-se a análise descritiva, por meio de frequências absolutas e relativas, medidas de tendência central (média e mediana) e de dispersão (desvio-padrão, mínimo-máximo). O teste Kolmogorov-Smirnov foi aplicado para avaliação da aderência das variáveis quantitativas à distribuição normal. As variáveis paramétricas foram apresentadas na forma de média e desvio-padrão, enquanto as demais estão descritas como mediana e valores mínimo-máximo. Foram realizados os testes Qui-quadrado de Pearson para a análise dos motivos de alteração dos cardápios e a adequação dos nutrientes; Kruskal-Wallis e Mann-Whitney para a comparação de medianas; Wilcoxon para a comparação das medianas dos nutrientes entre os cardápios planejados e os produzidos nas unidades e correlações de Spearman utilizadas para a análise de variáveis quantitativas. Em todas as análises o nível de significância considerado foi de $5 \%(p<0,05)$.

\section{RESULTADOS}

Observou-se que dos 365 cardápios analisados, 286 (78,4\%) sofreram alteração em relação ao planejado pelo município, sem diferenças significantes entre os distritos sanitários $(p=0,274)$. Como principal motivo para tais alterações, identificou-se a falta de ingredientes

(51,7\%). Além disso, o não cumprimento do cardápio planejado sem motivo aparente (19,6\%), a utilização de ingredientes próximos à data de vencimento (13,4\%), a baixa aceitação de determinadas preparações por parte das crianças $(11,5 \%)$, a falta de planejamento do pré-preparo $(5,6 \%)$ e a falta de equipamentos na unidade $(2,1 \%)$ também foram apontados, pelos manipuladores de alimentos, como motivos para as alterações de cardápios.

Foram identificadas diferenças estatisticamente significantes entre os distritos no tocante aos motivos para alteração dos cardápios: baixa aceitação de determinadas preparações por parte das crianças $(p<0,001)$ com maior prevalência nos distritos Leste e Pampulha, não cumprimento do cardápio planejado sem motivo aparente $(p<0,001)$ com maior prevalência no distrito do Barreiro, falta de ingredientes $(p<0,001)$ com maior prevalência no distrito Nordeste, utilização de ingredientes próximos à data de vencimento $(p<0,001)$ com maior prevalência no distrito Oeste e falta de planejamento do pré-preparo $(p=0,024)$ com maior prevalência nos distritos Nordeste e Leste.

No que se refere aos índices avaliadores da produção e distribuição da alimentação escolar (Tabela 1), concernentes à porção ofertada e as porções consumidas pelas crianças, não foram encontradas diferenças significantes entre os distritos sanitários $(p=0,220$ e $p=0,129$, respectivamente). Já quanto à porção dos colaboradores $(p=0,017)$, ao resto ingestão $(p=0,008)$ e sobras limpa $(p=0,002)$ e suja $(p=0,003)$ no município de Belo Horizonte, observou-se que houve diferença estatisticamente significante entre pelo menos um distrito sanitário.

Ao analisar os valores nutricionais dos cardápios planejados pelo município e produzidos nas unidades, percebeu-se que para o período integral, a maioria das medianas foi inferior aos valores estipulados pelo PNAE, em ambas as faixas etárias. O mesmo ocorreu no período parcial para a faixa etária de quatro a cinco anos. Em contrapartida, a faixa etária de um a três anos desse período apresentou medianas superiores aos valores estabelecidos pelo PNAE (Tabela 2). 
Tabela 1. Caracterização dos índices avaliadores da produção e distribuição da alimentação escolar em Belo Horizonte/MG, 2012/2013.

\begin{tabular}{|c|c|c|c|c|c|c|}
\hline $\begin{array}{l}\text { Município/ } \\
\text { Distritos } \\
\text { sanitários }\end{array}$ & $\begin{array}{l}\text { Porção ofertada } \\
\text { aluno (g) }\end{array}$ & $\begin{array}{l}\text { Porção consumida } \\
\text { aluno }(\mathrm{g})\end{array}$ & $\begin{array}{c}\text { Porção } \\
\text { consumida } \\
\text { colaboradores } \\
\text { (g) }\end{array}$ & $\begin{array}{c}\text { Resto ingestão } \\
(\%)\end{array}$ & $\begin{array}{c}\text { Sobra limpa } \\
(\%)\end{array}$ & $\begin{array}{l}\text { Sobra suja } \\
\qquad \%)\end{array}$ \\
\hline Belo Horizonte & $\begin{array}{c}246,00^{1} \\
(90,00-1190,00)\end{array}$ & $\begin{array}{c}170,00^{1} \\
(78,00-456,00)\end{array}$ & $\begin{array}{c}397,00^{1} \\
(0,00-960,00)\end{array}$ & $\begin{array}{c}7,08^{1} \\
(0,00-30,50)\end{array}$ & $\begin{array}{c}0,00^{1} \\
(0,00-58,50)\end{array}$ & $\begin{array}{c}8,55^{1} \\
(0,00-64,00)\end{array}$ \\
\hline Norte & $\begin{array}{l}223,01^{2} \\
(68,23)\end{array}$ & $\begin{array}{l}177,64^{2} \\
(74,83)\end{array}$ & $\begin{array}{l}440,33^{2} \\
(89,36)\end{array}$ & $\begin{array}{l}6,55^{2} \\
(5,60)\end{array}$ & $\begin{array}{c}0,00^{1} \\
(0,00-34,00)\end{array}$ & $\begin{array}{l}13,30^{2} \\
(13,09)\end{array}$ \\
\hline Nordeste & $\begin{array}{c}252,88^{2} \\
(62,32)\end{array}$ & $\begin{array}{l}164,40^{2} \\
(44,92)\end{array}$ & $\begin{array}{c}400,55^{2} \\
(52,17)\end{array}$ & $\begin{array}{l}11,33^{2} \\
(6,80)\end{array}$ & $\begin{array}{c}0,00^{1} \\
(0,00-16,40)\end{array}$ & $\begin{array}{r}24,76^{2} \\
(9,16)\end{array}$ \\
\hline Leste & $\begin{array}{c}264,50^{1} \\
(128,00-669,00)\end{array}$ & $\begin{array}{l}190,06^{2} \\
(63,54)\end{array}$ & $\begin{array}{l}425,00^{2} \\
(171,59)\end{array}$ & $\begin{array}{l}10,51^{2} \\
(7,47)\end{array}$ & $\begin{array}{c}0,00^{1} \\
(0,00-26,10)\end{array}$ & $\begin{array}{l}10,73^{2} \\
(11,71)\end{array}$ \\
\hline Centro-Sul & $\begin{array}{l}343,09^{2} \\
(218,96)\end{array}$ & $\begin{array}{c}229,27^{2} \\
(96,91)\end{array}$ & $\begin{array}{l}381,54^{2} \\
(214,2)\end{array}$ & $\begin{array}{l}5,51^{2} \\
(4,17)\end{array}$ & $\begin{array}{c}5,66^{1} \\
(0,00-42,90)\end{array}$ & $\begin{array}{l}6,05^{2} \\
(3,6)\end{array}$ \\
\hline Oeste & $\begin{array}{l}243,85^{2} \\
(51,39)\end{array}$ & $\begin{array}{l}179,17^{2} \\
(46,78)\end{array}$ & $\begin{array}{l}499,88^{2} \\
(127,40)\end{array}$ & $\begin{array}{l}13,04^{2} \\
(4,99)\end{array}$ & $\begin{array}{c}0,00^{1} \\
(0,00-37,50)\end{array}$ & $\begin{array}{c}15,46^{2} \\
(9,7)\end{array}$ \\
\hline Noroeste & $\begin{array}{l}260,52^{2} \\
(100,31)\end{array}$ & $\begin{array}{l}173,72^{2} \\
(47,54)\end{array}$ & $\begin{array}{l}366,00^{2} \\
(167,69)\end{array}$ & $\begin{array}{l}8,05^{2} \\
(5,16)\end{array}$ & $\begin{array}{c}3,52^{1} \\
(0,00-58,50)\end{array}$ & $\begin{array}{c}4,68^{1} \\
(0,00-31,10)\end{array}$ \\
\hline Barreiro & $\begin{array}{c}264,00^{2} \\
(78,57)\end{array}$ & $\begin{array}{l}183,62^{2} \\
(49,90)\end{array}$ & $\begin{array}{l}384,46^{2} \\
(121,50)\end{array}$ & $\begin{array}{l}4,88^{2} \\
(3,77)\end{array}$ & $\begin{array}{c}8,87^{1} \\
(0,00-26,90)\end{array}$ & $\begin{array}{l}8,28^{2} \\
(7,26)\end{array}$ \\
\hline Pampulha & $\begin{array}{l}217,65^{2} \\
(70,28)\end{array}$ & $\begin{array}{c}202,25^{2} \\
(69,15)\end{array}$ & $\begin{array}{c}210,00^{1} \\
(0,00-960,00)\end{array}$ & $\begin{array}{l}6,24^{2} \\
(2,48)\end{array}$ & $\begin{array}{l}10,08^{2} \\
(9,01)\end{array}$ & $\begin{array}{l}6,01^{2} \\
(4,17)\end{array}$ \\
\hline Venda Nova & $\begin{array}{l}292,20^{2} \\
(106,49)\end{array}$ & $\begin{array}{c}157,50^{1} \\
(126,00-248,00)\end{array}$ & $\begin{array}{l}321,75^{2} \\
(62,89)\end{array}$ & $\begin{array}{l}11,22^{2} \\
(5,51)\end{array}$ & $\begin{array}{c}0,00^{1} \\
(0,00-0,00)\end{array}$ & $\begin{array}{l}18,42^{2} \\
(12,18)\end{array}$ \\
\hline
\end{tabular}

${ }^{1}$ Mediana (min-max)

${ }^{2}$ Média (desvio-padrão)

Detectou-se diferença na maioria das medianas dos nutrientes analisados ao comparar cardápio planejado x produzido $(\mathrm{p}<0,05)$, exceto entre lipídeo $(p=0,101)$.

No que diz respeito à adequação, observou-se que a maior taxa percentual se fez presente nos cardápios planejados para a faixa etária de um a três anos, sendo 45,7\% de adequação para a fibra. Já nos cardápios produzidos a maior adequação foi para a faixa etária supracitada, sendo ferro o nutriente com o maior percentual $(33,4 \%)$. Ademais, verificou-se que o cálcio foi o nutriente com menor taxa de adequação para a faixa etária de quatro a cinco anos, com valores de $0,30 \%$ para cardápios planejados e 0,80\% para cardápios produzidos (Tabela 3).

Identificou-se correlações proporcionais entre a quantidade de alimento produzida com a porção consumida pelos alunos $(r=0,198$; $\mathrm{p}<0,001)$ e com a porcentagem de sobra limpa $(r=0,267 ; p<0,001)$ e inversamente proporcional com a porcentagem de sobra suja $(r=-0,255$; $p<0,001$ ). Além disso, a porcentagem de sobra suja correlacionou-se positivamente com a porcentagem de resto ingestão $(r=0,143 ; p=0,006)$. Houve ainda correlação negativa entre a porcentagem de sobra limpa com a porcentagem de resto ingestão ( $r=-0,254 ; p<0,001)$. Já o resto ingestão per capita correlacionou-se positivamente com a porção ofertada $(r=0,130 ; p=0,013)$ e negativamente com a consumida $(r=-0,122$; $\mathrm{p}=0,020$ ) pelo aluno (Figura 1).

\section{DISCUSSÃO}

Por meio do estudo, foi identificado um elevado índice de alteração de cardápios produzidos 
nas unidades de educação infantil em relação aos planejados pelo município, tendo como principal alegação a falta de ingredientes. Relatado por manipuladores de alimentos, esse motivo pode ser uma consequência da falta de conferência de quantidade e qualidade durante o recebimento dos gêneros nas unidades. Outro fato que pode ser apontado como justificativa é a utilização de ingredientes e alimentos de forma desordenada por parte dos manipuladores, não seguindo o que foi previamente estabelecido por, na maioria das vezes, desconhecerem a relevância desse ato.

Tabela 2. Energia e nutrientes dos cardápios planejados e produzidos em comparação aos valores de referência utilizados pelo Programa Nacional de Alimentação Escolar em unidades de educação infantil de período integral* e parcial** em Belo Horizonte/MG, 2012/2013.

\begin{tabular}{|c|c|c|c|c|}
\hline \multirow{2}{*}{ Energia e nutrientes } & \multicolumn{2}{|c|}{ PNAE* } & \multirow[b]{2}{*}{ Planejado } & \multirow[b]{2}{*}{ Produzido } \\
\hline & 1 a 3 anos & 4 a 5 anos & & \\
\hline Energia (kcal) & 300,00 & 400,00 & $252,34(108,10-689,70)$ & $232,97(65,00-942,50)$ \\
\hline Carboidrato (g) & 48,80 & 65,00 & $33,81(16,00-135,20)$ & $28,50(6,00-127,40)$ \\
\hline Proteína (g) & 9,40 & 12,50 & $15,10(5,30-37,70)$ & $12,12(2,60-49,60)$ \\
\hline Lipídeo (g) & 7,50 & 10,00 & $6,59(0,60-21,00)$ & $6,03(0,70-119,40)$ \\
\hline Fibra (g) & 5,70 & 7,50 & $4,51(2,10-9,10)$ & $3,80(0,90-20,80)$ \\
\hline Vitamina A ( $\mu \mathrm{g})$ & 90,00 & 120,00 & $85,40(0,00-745,20)$ & $47,14(0,00-981,90)$ \\
\hline Vitamina C (mg) & 5,00 & 8,00 & $4,69(0,00-99,00)$ & $3,30(0,00-225,10)$ \\
\hline Cálcio (mg) & 150,00 & 240,00 & $41,30(11,80-193,00)$ & $32,85(0,10-242,30)$ \\
\hline Ferro (mg) & 2,10 & 3,00 & $2,80(0,60-29,00)$ & $2,01(0,50-148,80)$ \\
\hline Zinco (mg) & 0,90 & 1,50 & $1,73(0,60-7,80)$ & $1,70(0,00-12,80)$ \\
\hline Magnésio (mg) & 24,00 & 39,00 & $47,00(14,80-100,10)$ & $32,52(0,30-199,20)$ \\
\hline \multirow{2}{*}{ Energia e nutrientes } & \multicolumn{2}{|c|}{ PNAE** } & & \\
\hline & 1 a 3 anos & 4 a 5 anos & Planejado & Produzido \\
\hline Energia (kcal) & 200,00 & 270,00 & $252,34(108,10-689,70)$ & $232,97(65,00-942,50)$ \\
\hline Carboidrato (g) & 32,50 & 43,90 & $33,81(16,00-135,20)$ & $28,50(6,00-127,40)$ \\
\hline Proteína (g) & 6,30 & 8,40 & $15,10(5,30-37,70)$ & $12,12(2,60-49,60)$ \\
\hline Lipídeo (g) & 5,00 & 6,80 & $6,59(0,60-21,00)$ & $6,03(0,70-119,40)$ \\
\hline Fibra (g) & 3,80 & 5,00 & $4,51(2,10-9,10)$ & $3,80(0,90-20,80)$ \\
\hline Vitamina A ( $\mu g)$ & 60,00 & 80,00 & $85,40(0,00-745,20)$ & $47,14(0,00-981,90)$ \\
\hline Vitamina C (mg) & 3,00 & 5,00 & $4,69(0,00-99,00)$ & $3,30(0,00-225,10)$ \\
\hline Cálcio (mg) & 100,00 & 160,00 & $41,30(11,80-193,00)$ & $32,85(0,10-242,30)$ \\
\hline Ferro (mg) & 1,40 & 2,00 & $2,80(0,60-29,00)$ & $2,01(0,50-148,80)$ \\
\hline Zinco (mg) & 0,60 & 1,00 & $1,73(0,60-7,80)$ & $1,70(0,00-12,80)$ \\
\hline Magnésio (mg) & 16,00 & 26,00 & $47,00(14,80-100,10)$ & $32,52(0,30-199,20)$ \\
\hline
\end{tabular}


Tabela 3. Adequação dos cardápios planejados e produzidos nas unidades de educação infantil em comparação aos valores de referência utilizados pelo Programa Nacional de Alimentação Escolar em unidades de educação infantil em Belo Horizonte/MG, 2012/2013.

\begin{tabular}{lcccc}
\hline & \multicolumn{3}{c}{ Adequação (\%) } \\
\hline \multirow{2}{*}{ Energia e Nutriente } & \multicolumn{2}{c}{ Planejado } & \multicolumn{2}{c}{ Produzido } \\
\cline { 2 - 5 } & $\mathbf{1 - 3}$ anos & $\mathbf{4 - 5}$ anos & $\mathbf{1 - 3}$ anos & $\mathbf{4 - 5}$ anos \\
\hline Energia & $39,70 \%$ & $30,40 \%$ & $32,90 \%$ & $23,00 \%$ \\
Carboidrato & $24,60 \%$ & $6,00 \%$ & $21,70 \%$ & $11,00 \%$ \\
Proteína & $20,30 \%$ & $28,50 \%$ & $27,40 \%$ & $26,60 \%$ \\
Lipídeo & $21,10 \%$ & $14,80 \%$ & $16,90 \%$ & $15,90 \%$ \\
Fibra & $45,70 \%$ & $18,10 \%$ & $23,70 \%$ & $13,70 \%$ \\
Vitamina A & $17,40 \%$ & $11,00 \%$ & $9,10 \%$ & $7,70 \%$ \\
Vitamina C & $22,90 \%$ & $10,70 \%$ & $15,70 \%$ & $12,30 \%$ \\
Cálcio & $2,60 \%$ & $0,30 \%$ & $2,30 \%$ & $0,80 \%$ \\
Ferro & $19,10 \%$ & $39,70 \%$ & $33,40 \%$ & $30,10 \%$ \\
Zinco & $12,30 \%$ & $31,00 \%$ & $14,90 \%$ & $23,30 \%$ \\
Magnésio & $9,70 \%$ & $24,70 \%$ & $22,00 \%$ & $33,20 \%$ \\
\hline
\end{tabular}

Acredita-se que isto ocorra em função da falta de capacitações sistematizadas para esses profissionais, que os sensibilizem para a importância do seguimento do cardápio planejado e para a utilização das fichas técnicas (receituários) disponibilizadas nas unidades. Ademais, cabe salientar que o profissional nutricionista realiza supervisões nesses locais a cada 10 ou 15 dias, pois na rede municipal há um profissional para cada 15 unidades educacionais, o que dificulta as orientações da rotina diária, bem como a educação continuada dos manipuladores de alimentos.

Estudo similar mostra a importância da participação de manipuladores de alimentos na escolha das preparações que compõe o cardápio das unidades, uma vez que eles possuem grande conhecimento dos hábitos alimentares das crianças devido à convivência diária. Contudo, o planejamento de cardápio é uma atribuição do profissional de nutrição habilitado, pois este irá garantir a adequação nutricional da refeição produzida de acordo com a faixa etária e perfil epidemiológico do pré-escolar ${ }^{16}$. Na rede das escolas públicas municipais de Belo Horizonte MG, os cardápios são planejados por nutricionistas da Gerência de Planejamento e Avaliação Nutricional (GEPAVN) da Secretaria Municipal Adjunta de Segurança Alimentar e Nutricional (SMASAN). Atualmente, trabalha-se com uma seleção de 20 cardápios base, únicos para todas as unidades de educação infantil, que são alternados ao longo do ano. Essa gerência trabalha de forma participativa com a Gerência de Alimentação Escolar e Assistência Nutricional (GEALE), onde estão inseridos os profissionais supervisores da alimentação escolar. Verifica-se que há um esforço conjunto dessas gerências para adequação dos cardápios e que gradativamente os manipuladores de alimentos estão sendo conscientizados da importância de seguimento dos mesmos, sendo ouvidos quanto a demandas de mudanças, especialmente aquelas relacionadas à aceitação das preparações. ${ }^{17}$

Considerando o processo de produção e distribuição da alimentação escolar, pode-se destacar que a mediana encontrada para a porção consumida $(170,00 \mathrm{~g})$ foi inferior a ofertada 
$(246,00 g)$ ao aluno. Ademais, destaca-se que a porção consumida está proporcionalmente relacionada com a quantidade produzida de alimentos e sobra limpa e ainda que a porção ofertada está correlacionada positivamente com o resto ingestão e a porção consumida está correlacionada negativamente com o resto ingestão (Figura 1). Uma estratégia para a minimização desse desperdício alimentar pode ser traçada por meio da utilização do sistema de autosserviço em todas as unidades de educação infantil. Belik $\&$ Chaim ${ }^{18}$ apontam que esse sistema se encontra disponível em apenas 11,5\% dos municípios inscritos no Prêmio Gestor Eficiente da Merenda Escolar, proposto pela Organização Não Governamental Ação Fome Zero, evidenciando que na maioria das unidades de ensino são os manipuladores de alimentos que realizam o porcionamento das preparações. O sistema de autosserviço pode ajudar nas atividades de educação alimentar e na redução do desperdício uma vez que esse procedimento oferece autonomia ao aluno, representando uma forma deste avaliar gosto, aspecto e apresentação do cardápio produzido. Contudo, o funcionamento adequado desse sistema apenas é possível com um acompanhamento de profissionais qualificados que darão o suporte necessário aos alunos. Adicionalmente, a maioria das escolas continua optando pelo sistema tradicional, tendo grande resistência para as inovações referentes à questão alimentar.

Figura 1. Correlações verificadas na alimentação escolar em Belo Horizonte - MG, 2012/2013.

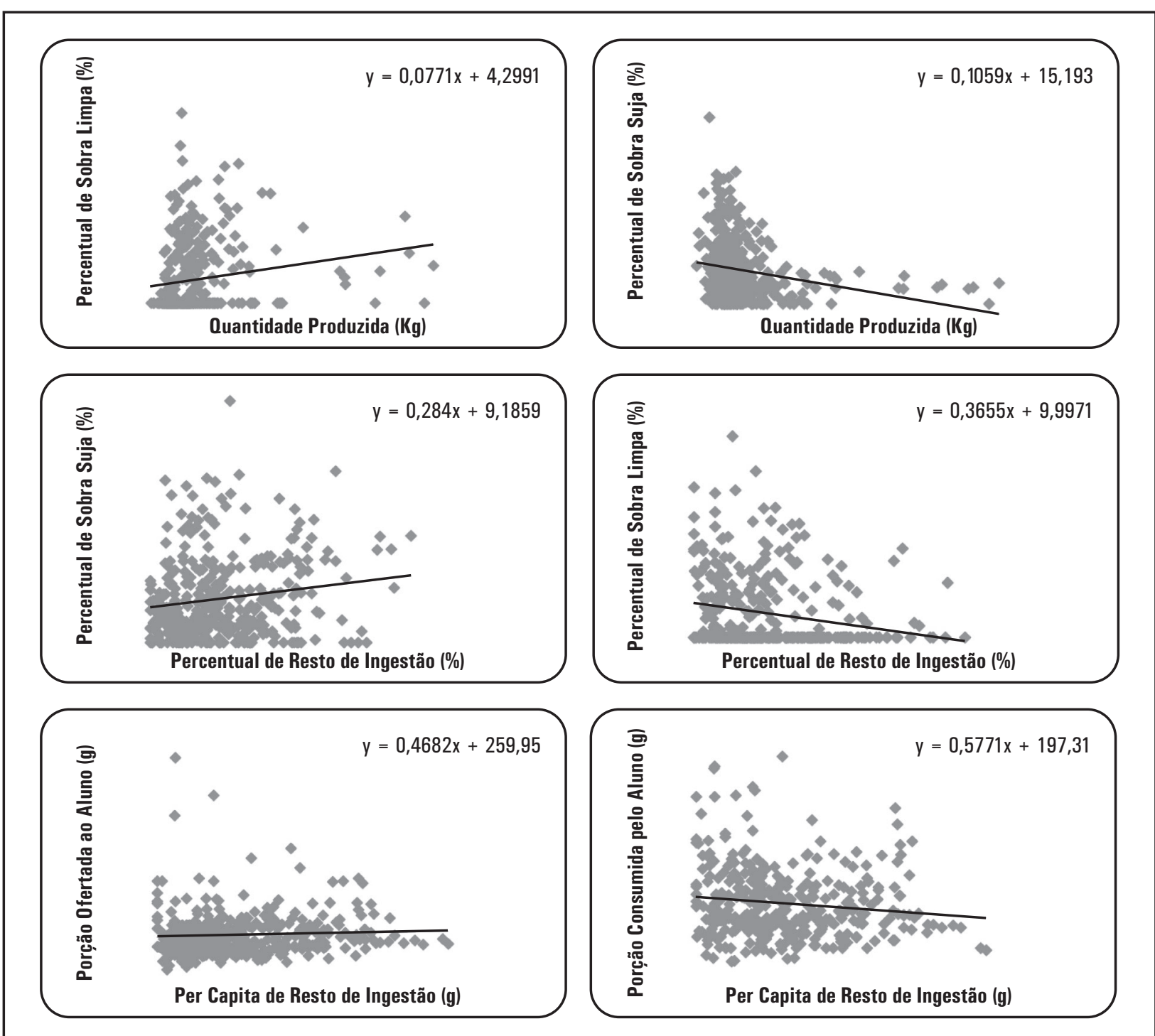


A porção consumida por colaboradores apresentou-se 2,3 vezes maior do que a porção consumida pelos alunos, podendo esse fato gerar influências que acarretarão em um aumento na demanda de gêneros alimentícios, na quantidade de alimentos produzidos e na quantidade de sobras e resto ingestão. Deve-se ponderar que com base na Resolução no 26 de 2013, apenas os alunos matriculados na atenção básica das redes públicas federal, estadual, do Distrito Federal e municipal têm direito a receber alimentação escolar pelo PNAE. ${ }^{5}$ No entanto, o município de Belo Horizonte complementa a verba do programa, permitindo que alguns colaboradores recebam a refeição principal sob critérios estabelecidos em portaria municipal: trabalhar em período integral, comer somente após a refeição dos escolares e respectivas repetições, em quantidades compatíveis com o planejamento dos escolares e tendo acesso ao mesmo cardápio ofertado ao público alvo, sem diferenciações. Verifica-se que ainda há grandes dificuldades e resistências para fazer valer a aplicação desses critérios nas unidades.

O desperdício alimentar pode ser medido por meio das sobras, onde os alimentos foram preparados e não consumidos e pelo resto, onde os alimentos foram servidos e não consumidos, sendo este representado pelo o que resta no prato do cliente. ${ }^{19}$ Assim sendo, foi verificado, no município, índice de resto ingestão superior à faixa considerada aceitável e este esteve proporcionalmente relacionado com a quantidade da refeição ofertada e inversamente com a porção consumida (Figura 1). Analisando as sobras limpa e suja, o índice médio obtido também ficou superior ao valor sugerido na literatura. ${ }^{14,15}$ Ademais, a sobre limpa esteve significativamente relacionada com o resto ingestão e a sobra suja inversamente relacionada com esse mesmo índice (Figura 1). Esse desperdício alimentar nas unidades de educação infantil sofre influências de vários aspectos como o planejamento inadequado para elaboração do cardápio, preferências alimentares das crianças e treinamento dos manipuladores para uma efetiva produção e distribuição. ${ }^{19}$
Outro aspecto influenciador é a naturalização da alimentação escolar, sendo percebida apenas como parte da rotina, sem relevância social. A alimentação deve ser desnaturalizada, buscando a criação de espaços para que esse tema seja discutido no ambiente escolar. Embora não seja simples, é importante que a alimentação ocupe espaço no projeto pedagógico das escolas, realizando atividades entre os docentes e demais funcionários envolvidos nesse ambiente e promovendo atividades integradoras que ampliem a percepção desse assunto pelos alunos. ${ }^{4}$

Esse índice elevado de resto ingestão e do somatório das sobras de produção e distribuição também pode ter associação direta com o não seguimento do per capita planejado pelo município, de acordo com a faixa etária, acarretando um porcionamento inadequado. Isso pode ser evidenciado em algumas UMEI e creches conveniadas à Prefeitura Municipal, onde a porção ofertada para crianças de um a três anos era semelhante à ofertada para crianças de quatro a cinco anos.

Ao considerar a adequação nutricional, o estudo mostrou que a maior parte dos cardápios planejados pelo município e dos cardápios produzidos nas unidades não atingiram os valores de referência estabelecidos pelo PNAE. Sobretudo, tais inadequações nutricionais fizeram-se mais frequentes nos grupos escolares pertencentes à faixa etária superior aos três anos de idade. Faz-se, portanto, recomendável uma readequação dos per capitas, em função do grupamento etário como sugerem Silva \& Gregório. ${ }^{20}$ Também, ainda sobre este aspecto, deve-se considerar o período de permanência da criança na unidade, pois os nutrientes avaliados apresentaram maior inadequação para o período integral, podendo ser explicado pelo fato de que o percentual de recomendação nutricional do PNAE para tal período é superior ao percentual recomendado para o período parcial.

Dentro desta problemática, verifica-se que as inadequações nutricionais encontradas para os cardápios planejados podem estar diretamente relacionadas a fragilidades no planejamento do mesmo. Gabriel et al. ${ }^{21}$ salienta sobre a

声


importância de se planejar adequadamente um cardápio, a fim de que as refeições programadas atendam às necessidades nutricionais da população a que se destina, respeitando suas características e hábitos alimentares.

Em contrapartida, as inadequações evidenciadas para os cardápios produzidos nas unidades, provavelmente se relacionam a variação de por parte dos manipuladores é um acontecimento constante. Porém também podem estar diretamente relacionadas a uma baixa aceitação da refeição produzida por parte dos pré-escolares, podendo esse fato ser solucionado por meio da execução de preparações saborosas e atrativas para a faixa etária, como afirma Abranches et al. ${ }^{22}$ Quanto aos aspectos diferenciais relevantes entre os cardápios supracitados, observaram-se percentuais de adequação inferiores para os cardápios produzidos em relação aos planejados, para ambos os períodos - parcial e integral.

No tocante à análise de adequação verificou-se que, em relação aos macronutrientes, tanto os cardápios planejados quanto os produzidos referentes ao período integral apresentaram ofertas insuficientes de carboidratos e lipídeos, enquanto o conteúdo proteico atingiu ou até mesmo ultrapassou as recomendações estabelecidas pelo PNAE para ambas as faixas etárias. Resultados semelhantes foram encontrados em estudo realizado por Longo-Silva et al. ${ }^{8}$ em que avaliou o consumo alimentar em creches públicas de São Paulo. O mesmo não ocorreu nas análises para o período parcial onde as inadequações se fizeram menos constantes, principalmente tratando-se do cardápio planejado referente à faixa etária de um a três anos. Concomitantemente, a adequação de fibras se fez de forma mínima, atingindo os valores recomendados apenas para os pré-escolares inseridos no período parcial e com idade até três anos. Tal fato pode ser decorrente da baixa oferta e aceitação de frutas, verduras e legumes pelas crianças. O estudo de Ciochetto et al. ${ }^{23}$ certificou-se de tal hipótese ao afirmar que a rejeição de alimentos fontes de fibras configura

uma constante entre os escolares da rede pública no Sul do Brasil.

Quanto aos micronutrientes observou-se que o cálcio foi o mineral mais afetado, estando abaixo da recomendação estabelecida, o que se assemelha às demais pesquisas realizadas no contexto escolar. ${ }^{22,}{ }^{24}$ Considerando a participação do cálcio na saúde óssea, é necessário atingir as recomendações da ingestão desse nutriente ${ }^{25}$. No entanto, vale ressaltar que a refeição investigada no presente estudo foi o almoço, a qual não constitui uma fonte importante deste nutriente.

Em relação ao zinco, os valores observados ultrapassaram a recomendação do PNAE. Sabe-se que o excesso deste mineral pode ser prejudicial uma vez que se associa à supressão da resposta imune e diminuição da Lipoproteína de Alta Densidade - HDL. ${ }^{26}$ No que diz respeito ao teor de ferro, encontra-se adequado conforme a recomendação do PNAE para a maioria dos cardápios como também para faixas etárias, o que é um aspecto favorável à saúde e ao estado nutricional das crianças, já que a deficiência orgânica do mesmo compromete diversas funções celulares e pode implicar, no grupo infantil, em prejuízos no desenvolvimento cognitivo, crescimento e estado imunológico. ${ }^{22}$

Para o magnésio todas as faixas etárias em todos os cardápios atingiram as recomendações. Este mineral é de extrema importância, pois se encontra presente nos ossos, tecidos moles, músculos e fluidos corpóreos atuando como cofator em mais de 300 sistemas enzimáticos. ${ }^{27}$

Também foram analisadas as adequações de Vitaminas A e C, sendo que, para ambas, os cardápios planejados apresentaram maiores percentuais de adequação, exceto para faixa etária de quatro a cinco anos no que diz respeito à vitamina C. Já os cardápios produzidos demonstraram adequação apenas para o teor de vitamina $C$ na faixa etária de um a três anos em pré-escolares pertencentes ao turno parcial. Em contrapartida Abranches et al. ${ }^{22}$ ao analisar a composição nutricional da merenda em creches privadas e públicas, encontrou valores adequados para a vitamina $C$. 
Os resultados referentes ao valor energético mostraram-se adequados apenas para os cardápios planejados e produzidos para pré-escolares pertencentes ao período integral enquadrados na faixa etária de um a três anos. Sobre esse aspecto, Abranches et al. ${ }^{22}$ enfatiza a importância de um aporte energético adequado, já que se este permanecer abaixo das necessidades da criança por um período de tempo prolongado, poderá despontar um possível prejuízo na utilização proteica pelo organismo prejudicando assim seu desenvolvimento e crescimento.

Como limitação do estudo, pode ser mencionada a utilização de apenas um per capita para todas as faixas etárias, o que pode gerar valores superestimados ou subestimados relativos ao ofertado e consumido pelo público escolar. Entretanto, seguiu-se o planejamento adotado pela prefeitura, que calcula os alimentos per capita, independentemente da idade.

Por fim, destaca-se como aspecto positivo deste estudo que foi possível a obtenção de um diagnóstico referente à alimentação em unidades de educação infantil do município de
Belo Horizonte, evidenciando a necessidade de mudanças no processo de planejamento, produção, distribuição e adequação nutricional da alimentação escolar. É essencial que os cardápios planejados sejam modulados e rigorosamente seguidos a fim de atender as especificidades do público em questão, contribuindo para uma alimentação que supra as necessidades do pré-escolar, respeitando a variação etária.

\section{CONCLUSÃO}

Conclui-se que o planejamento da merenda escolar deve ser reestruturado, contando com a capacitação sistematizada de manipuladores de alimentos e a presença frequente de um profissional qualificado para gerenciar processos desde o recebimento dos gêneros alimentícios até a distribuição da refeição. Uma melhor estruturação desse processo juntamente com atividades de educação alimentar e nutricional ocasionarão no decréscimo dos índices de desperdício alimentar, reduzindo gastos desnecessários nas unidades e melhorando qualitativamente e quantitativamente a alimentação escolar.

\section{REFERÊNCIAS}

1. Gomes, M J M, Nascimento, E G C. As multifacetas do excesso de peso na criança: uma revisão sistemática. Rev Bra. Ciên Saúde/Revista de Atenção à Saúde, 13(45): 70-79. DOI: 10.13037/ras.vol13n45.2667.

2. Andrade J, Bischoff LC, Bonetto L, Dias CP, Roncada C. Intervenções escolares para redução da obesidade infantil: uma revisão sistemática. Ciên Saúde. 2015; 8(2): 72-78. DOI: 10.15448/1983-652X.2015.2.19790

3. Sociedade Brasileira de Pediatria. Departamento de Nutrologia. Obesidade na infância e adolescência - Manual de Orientação. São Paulo: Sociedade Brasileira de Pediatria. Departamento de Nutrologia, 2008. Disponível em: <http://www. sbp.com.br/PDFs/Man Nutrologia_Obsidade.pdf>.

4. Barbosa NVS, Machado NMV, Soares MCV, Pinto ARR. Alimentação na escola e autonomia - desafios e possibilidades. Ciênc. saúde coletiva. 2013, 18(4): 937-45. DOI:10.1590/S1413-81232013000400005

5. Brasil. Ministério da Educação. Fundo Nacional de Desenvolvimento da Educação, Conselho Deliberativo, FNDE. Resolução RDC n² 26, de 17 de Junho de 2013. Brasília, DF, 2013. Disponível em: http://www.fnde.gov.br/fnde/legislacao/ resolucoes/item/4620-resolu\%C3\%A7\%C3\%A3o-cd-fnde-n\%C2\%BA-26,-de-17-de-junho-de-2013

6. Freitas MCS, Minayo MCS, Ramos LB, Fontes GV, Santos LA, Souza EC, et al. Escola: lugar de estudar e de comer. Ciênc. saúde coletiva. 2013, 18(4):979-85. DOI:10.1590/S1413-81232013000400010.

7. Magalhães TCA, Pires CN, Firmino HH, Franceschini SCC, Sant'Ana LFR. Aspectos relacionados à saúde infantil e principais alterações nutricionais em crianças brasileiras: revisão de literatura. Cad. saúde colet. (Rio J.). 2009, 17(2):433-52. 8. Longo-Silva G, Toloni MHA, Goulart RMM, Taddei JAAC. Avaliação do consumo alimentar em creches públicas em São Paulo, Brasil. Rev. paul. pediatr. 2012, 30(1):35-41.

9. Instituto Brasileiro de Geografia e Estatística - IBGE, em parceria com os Órgãos Estaduais de Estatística, Secretarias Estaduais de Governo e Superintendência da Zona Franca de Manaus - SUFRAMA. Censo, 2010. Disponível em: <http:// cidades.ibge.gov.br/download/mapa_e_municipios.php?lang=\&uf=mg>.

10. Browner WS, Newman TB, Cummings SR, Hulley SB. Estimando o tamanho de amostra e o poder estatístico: pontos básicos. In: Hulley SB, Cummings SR, Browner WS, Grady D, Hearst N, Newman TB, editors. Delineando a pesquisa clínica, uma abordagem epidemiológica. 2nd ed. Porto Alegre: Artmed; 2003. p.83-104. 
11. Issa RC, Moraes LF, Francisco RRJ, Santos LC, Anjos AFV, Pereira SCL. Alimentação escolar: planejamento, produção, distribuição e adequação. Rev Panam Salud Publica 2014; 35(2): 96-103.

12. Spegiorin L, Moura P. Monitoramento de sobras limpas: um passo para a redução do desperdício em Unidades de Alimentação e Nutrição (UAN's). Revista Salus-Guarapuava (PR). 2009, 3(1):15-22.

13. Soares ICC, Silva ER, Priore SE, Ribeiro RCL, Pereira MMLS, Pinheiro-Sant'ana HM. Quantificação e análise do custo da sobra limpa em unidades de alimentação e nutrição de uma empresa de grande porte. Rev Nutr. 2011, 24(4):593-604. DOI: 10.1590/S1415-52732011000400008

14. Vaz CS. Alimentação de coletividade: uma abordagem gerencial. Manual Prático do Gestor de Serviços de Refeições Coletivas. 2nd ed. Brasilia: Ed. Metha; 2003.

15. Vaz CS. Restaurantes: controlando custos e aumentando lucros. Brasília: Ed. Metha; 2006.

16. Carvalho AT, Muniz VM, Gomes JF, Samico I. Programa de alimentação escolar no município de João Pessoa - PB, Brasil: as merendeiras em foco. Interface comun. saúde educ. 2008, 12(27):823-34.

17. Prefeitura Municipal de Belo Horizonte. Secretaria Municipal de Políticas Sociais. Secretaria Municipal de Segurança Alimentar e Nutricional. Portaria SMASAN/SMED n001/2013, de 09 de julho de 2013. Disponível em: <http://portal6. pbh.gov.br/dom/iniciaEdicao.do?method=DetalheArtigo\&pk=1103148>.

18. Belik W, Chaim NA. O programa nacional de alimentação escolar e a gestão municipal: eficiência administrativa, controle social e desenvolvimento local. Rev Nutr. 2009, 22(5):595-607.

19. Zandonadi, HS, Maurício, AA. Avaliação do índice de resto-ingesta, de refeições consumidas por trabalhadores da construção civil no município de Cuiabá, MT. Hig. aliment. 2012, 26(207):64-70.

20. Silva MMDC, Gregório EL. Avaliação da composição nutricional dos cardápios da alimentação escolar das escolas da rede municipal de Taquaraçu de Minas - MG. HU Rev. 2012, 37(3):387-94.

21. Gabriel CG, Costa LCF, Calvo MCM, Vasconcelos FAG. Planejamento de cardápios para escolas públicas municipais: reflexão e ilustração desse processo em duas capitais brasileiras. Rev Nutr. 2012, 25(3):363-72. DOI: 10.1590/ S1415-52732012000300006.

22. Abranches MV, Paula HAA, Mata GMSC, Salvador BC, Marinho MS, Priore SE. Avaliação da adequação alimentar de creches pública e privada no contexto do programa nacional de alimentação escolar. Nutrine Rev Soc Bras. Aliment Nutr. 2009, 34(2): 43-57.

23. Ciochetto CR, Orlandi SP, Vieira MFA. Consumo de frutas e vegetais em escolares da rede pública no Sul do Brasil. Sociedade Latino Americana de Nutrição. Órgão Oficial da Sociedade Latino Americana de Nutrição. 2012, 62(2).

24. Longo SG, Toloni MHA, Goulart RMM, Taddei JAAC. Avaliação do consumo alimentar em creches públicas em São Paulo, Brasil. Rev Paul Pediatr 2012; 30(1): 35-41. DOI: 10.1590/S0103-05822012000100006.

25. Pereira GAP, Genaro PS, Pinheiro MM, Szejnfeld VL, Martini LA. Cálcio dietético - estratégias para otimizar o consumo. Rev bras reumatol 2009, 49(2):164-80.

26. Jen M, Yan AC. Syndromes associated with nutritional deficiency and excess. Clin Dermatol. 2010, 28(6):669-85. DOI:10.1016/j.clindermatol.2010.03.029.

27. Leal KK, Schneider BC, França GVA, Gigante DP, Santos I, Assunção MCF. Qualidade da dieta de pré-escolares de 2 a 5 anos residentes na área urbana da cidade de Pelotas, RS. Rev Paul Pediatr. 2015; 33(3): 311-318. DOl:10.1016/j. rpped.2015.05.002

Recebido em: 22 de julho de 2014. Aprovado em: 12 de setembro de 2015. 